\title{
La Dictadura de Duvalier en Haití y la Política de Contención al Comunismo en las repúblicas insulares del Caribe, $(1957-1963)$
}

\author{
Por Carlos Alberto Murgueitio Manrique
}

\begin{abstract}
Resumen
Este pequeño trabajo busca explicar la estrecha relación existente entre la naturaleza de los regímenes dictatoriales en las repúblicas insulares del Caribe, específicamente del gobierno de Duvalier I en Haití y la lógica del comportamiento político - diplomático y militar propio de la época, enmarcado dentro de los lineamientos de la Guerra Fría y respaldado por los gobiernos de los Estados Unidos de América.

Además, el artículo trata de definir y caracterizar la dictadura personalista de Duvalier I, enfatizando en sus métodos de implementación del terror para mantener el orden interno, evaluando sus programas de desarrollo económico, y las respuestas de fuerza formuladas en contra de la revolución cubana y su grado de influencia en las Antillas y frente a gobiernos democráticos que amenazaban su supervivencia.
\end{abstract}

Palabras claves: dictadura, comunismo, democracia, diplomacia.

\begin{abstract}
This small piece of work shows the strong relation between the nature of the dictatorial regimes in the insular republics of the Caribbean, specially Duvalier I government in Haiti and the political - diplomatic and military behavior of the time marked inside the lines of the Cold War and supported by the governments of the United States of America.

Besides, the article tries to define and characterize the personalist dictatorship of Duvalier I, remarking in his methods in the implementation of terror to maintain the internal order, evaluating his programs in economical development and his reactions of force formulated against the Cuban revolution and its influence in the Antilles and in front of democratic governments that menaced its survival.
\end{abstract}

Keywords: dictatorship, communism, democracy, diplomacy.

La distancia ideológica partidista presente en los diferentes gobiernos estadounidenses durante las décadas posteriores a la segunda posguerra, fuesen estos republicanos o demócratas, condicionaba los métodos y los recursos operativos para desarrollar los proyectos geopolíticos, tanto mundiales como hemisféricos. Los demócratas con Franklin D. Roosevelt y Harry Truman habían jugado un papel fundamental en la construcción de las nuevas instituciones internacionales que regularían el nuevo orden mundial, buscando influir en los acontecimientos internacionales a través de políticas de reconstrucción económica y promoción de la democracia representativa, mientras los republicanos con Dwigt Eisenhower, respaldaban abiertamente las

\footnotetext{
*Artículo Tipo 2: de reflexión según Colciencias.

** Politólogo - Universidad de los Andes, Bogotá. Master en Historia Contemporánea de América Universidad Central de Venezuela, Caracas. Profesor Asistente, Departamento de Historia - Universidad del Valle, Cali. Correo: carlosmurgueitio94@ yahoo.com
} 
políticas de fuerza y gobiernos de facto para contener la expansión del comunismo, convocando el apoyo de sus aliados miembros de la recién conformada ONU para impedir su propagación, tal y como sucedió en la península coreana tras el triunfo de la revolución maoísta en China continental.

Sin embargo, el combate emprendido contra la eventual "expansión del comunismo" por el mundo en las décadas de 1950 y 1960, obligaba y establecía la necesidad de establecer lineamientos de contención más allá de los límites del mundo occidental. La contención al comunismo definida en la Doctrina Truman y puesta a funcionamiento por el gobierno Eisenhower requería mecanismos de diversa índole que mezclaban estrategias de todo tipo y en todos los lugares del mundo, como la seguridad económica y militar de Europa, la asistencia al desarrollo en el denominado Tercer Mundo, las alianzas de cooperación militar con gobiernos de confianza en las diferentes zonas de influencia y el mantenimiento de bases militares estratégicas para el comercio en todos los mares y océanos.

Las políticas de contención empleadas tanto por Dwigt Eisenhower como posteriormente por John F. Kennedy tuvieron un mismo objetivo general: impedir la propagación del "comunismo" fuera de las zonas de influencia tradicionales de la Unión Soviética y de China Popular. En pocas palabras, mantener el orden dentro de las zonas de influencia de los Estados Unidos en el Rimland ${ }^{1}$ continental y el Nuevo Mundo, sin importar los medios, fuesen estos políticos, económicos o militares.

En múltiples ocasiones se debió recurrir al desarrollo de estrategias de cuestionable moralidad política para un país que se denominaba a sí mismo como "el arsenal de la democracia", al promover abiertamente gobiernos militares dictatoriales, como sucedió durante la administración republicana de Eisenhower, o mantenerlos y apoyarlos subrepticiamente como lo hicieron los gobiernos demócratas de John F. Kennedy y Lyndon Johnson. Este apoyo constante corresponde al caso de Haití, que por estar tan cerca de la isla de Cuba se convertiría en pieza fundamental del anticomunismo practicado desde 1959 con mayor intensidad que nunca. Ambos gobiernos norteamericanos generaron lazos de entendimiento y cooperación con el gobierno militar de François Duvalier, o Duvalier I, cuya perduración del poder en esa parte de la isla de La Española, requería de partidas de apoyo económico y militar que sus aliados debían facilitarle sin mayores requerimientos.

Estos recursos terminaban siendo destinados al fortalecimiento de un gobierno autocrático y de su camarilla de colaboradores que se respaldaban a partir del empleo de efectivos armados que tenían como fin generar suficiente terror en la población para impedir brotes de manifestación y rechazo general a sus

\footnotetext{
${ }^{1}$ El Rimland continental se puede definir como una especie de cinturón geográfico, territorial y poblacional, que incluía tanto a Japón, como al sudeste asiático, el subcontinente indio, Persia y el Medio Oriente, además de la Europa occidental, en torno a esferas de influencia diplomática y militar de los Estados Unidos en el Viejo Mundo, durante la Guerra Fría. Estas alianzas de cooperación eran formalizadas tenían por fin último impedir la propagación del comunismo por el mundo. La OTAN, la SEATO e inclusive la TIAR, que incluía a los Estados Americanos se constituyeron como fórmulas de contención al comunismo durante la era de la posguerra. En: Spykman, Nicholas. Estados Unidos frente al mundo. México, Fondo de Cultura Económica, 1955.
} 
impopulares políticas. El gobierno de Duvalier I se convertiría, a partir de los acontecimientos revolucionarios en Cuba, en un bastión defensivo de los intereses estadounidenses en el Caribe y su respaldo se mantuvo constante en los círculos de poder de Washington, tanto en los gobiernos republicanos como en los demócratas, cuestión que explica su grado de perdurabilidad en el poder pese a las amenazas internas y externas que se tejían contra su gobierno.

Los diferentes gobiernos de los Estados Unidos que se sucedieron en el poder durante el clímax de la Guerra Fría en el Caribe, adoptaron políticas blandas frente a sus excesos. Las informaciones sobre los sucesos en la república insular se conocían ampliamente por la difusión de las noticias efectuadas por miles de exiliados políticos y sacerdotes católicos forzados a dejar el país por las amenazas contra sus vidas bajo el gobierno de Duvalier. Sin embargo, la lógica geopolítica vigente e imperante en el momento, la necesidad de establecer alianzas estratégicas con líderes anticomunistas en el hemisferio y el objetivo de consolidar un cordón sanitario de seguridad o contención frente a la posible expansión de los ideales, formas de lucha y proyecto político de la revolución cubana, obligó y hasta cierto punto favoreció la permanencia de la estrategia de seguridad hemisférica contrarrevolucionaria, patrocinada por los Estados Unidos y adoptada por sus gobiernos amigos en la región durante buena parte del siglo XX.

\section{Definición del enemigo común, fórmula para contener al comunismo en el Caribe (1945 - 1963)}

El triunfo militar de los Estados Unidos frente a los imperios del Eje durante la Segunda Guerra Mundial conllevó al alejamiento doctrinario de la política civilista de la buena vecindad en boga durante la era de Franklin Delano Roosevelt. La convivencia o coexistencia pacífica de los gobiernos liberales y democráticos con los regímenes de izquierda tanto reformistas como de orientación marxista no sobrevivieron a los cambios producidos en la arena internacional tras el fin de la Segunda Guerra Mundial (Powaski, 2000). La nueva situación obligaba a radicalizar los esfuerzos norteamericanos hacia políticas de contención o disuasión estratégica frente a la Unión Soviética y sus satélites del este de Europa, al mismo tiempo que a impedir una expansión mayor del impulso revolucionario por el mundo colonial en medio de las luchas emprendidas por los nativos africanos y asiáticos para lograr su emancipación frente a los imperialismos europeos.

La realidad de la posguerra volvía inevitable la radicalización de las posiciones de los vencedores. Tanto para la Unión Soviética como para los Estados Unidos de América, la delimitación de las zonas de influencia donde ejercerían un dominio hegemónico sobre los demás estados y sus gobiernos, eran los temas fundamentales sobre los que se construirían las políticas de seguridad en el futuro. Por eso era necesario incitar a sus aliados a conformar relaciones de colaboración por medio del patrocinio de estrategias de bloque contra el oponente y sus asociados. Además, el triunfo militar de las guerrillas comunistas en China en el año de 1949 complicaba la situación de las potencias occidentales, pues este modelo junto con el inspirado por la India y su independencia pacífica del imperio británico llenaba al mundo colonial de África y Asia de anhelos para luchar o negociar su emancipación política. 
De esta manera a los Estados Unidos les correspondía adoptar políticas de contención tanto estratégica como económica para impedir una mayor expansión del incendio revolucionario por el mundo colonial y semicolonial, soportando las estructuras de los imperios tradicionales en Africa y Asia y manteniendo gobiernos autocráticos de orientación anticomunista en América Latina. La fórmula del gobierno de Truman se enfocó en el otorgamiento de créditos para los países subdesarrollados con el fin de reproducir en estos estados los postulados del modelo de desarrollo liberal occidental (Escobar, 1996). Las inversiones debían destinarse a la construcción de infraestructura, a la distribución general de los servicios públicos, al fomento de los latifundios agro productivos con el fin de motivar la exportación de materias primas y utilizar los excedentes en inversiones útiles para su modernización económica.

Esta fiebre desarrollista fue de vital importancia ya que los regímenes militares buscaron materializar sus preceptos ideológicos nacionalistas a través del fomento de obras públicas y del fortalecimiento de sus aparatos punitivos, pero recurriendo constantemente al otorgamiento de empréstitos a la banca internacional o utilizando la inversión extranjera como combustible económico para la consecución de sus objetivos. En ambos casos era necesario contar con buenas relaciones en Washington, cuestión que lógicamente restringía la capacidad de maniobra en la arena internacional. Se sacrificaba así partes de la soberanía de los países a cambio del restablecimiento de las agendas de cooperación atractivas para los capitales de inversión y necesarias para la construcción de redes de asistencia militar.

La necesidad de obstaculizar la emergencia al poder de los sectores populares que con sus programas de expropiaciones y nacionalizaciones, ponían en peligro no solo al capital privado interno pero también a las inversiones internacionales, precisamente en momentos de paranoia internacional, se convirtió en un imperativo en muchos países del hemisferio, tanto en la región del Caribe y Centroamérica; Haití, Cuba, República Dominicana, Nicaragua, Guatemala, Honduras, Panamá, como en los Andes; Perú, Colombia y Venezuela. No es coincidencia que durante la década de 1950, correspondiente a los sucesivos gobiernos republicanos de Eisenhower, la mayor parte del hemisferio se hubiese transformado en un área gobernada por militares apoyados en menor o mayor intensidad por los Estados Unidos en un esfuerzo por mantener a raya a sus supuestos enemigos ideológicos, sacrificando tanto la democracia como los derechos humanos en esos pueblos.

Los gobiernos militares construyeron redes de solidaridad político - ideológica, Internacional de las Espadas ${ }^{2}$, con el propósito de ayudarse mutuamente en la

\footnotetext{
${ }^{2}$ Internacional de las Espadas. Apropiado concepto que utiliza la escuela historiográfica de Venezuela para referirse al proceso político vivido por buena parte de los países de América Latina y el Caribe durante la década de 1950. El fenómeno se generalizó desde 1952 y su duración terminó de manera circunstancial con el fin de la era Eisenhower y el inicio de la administración Kennedy. Este periodo, en donde la mayor parte de los países de la región pierden la institucionalidad democrática y esta es remplazada por gobiernos de facto, o pretorianos, incluye a los gobiernos previos al contexto de los años 1950, como el régimen de Rafael Leonidas Trujillo, en República Dominicana, el de Anastasio Somoza y su dinastía en Nicaragua, así como a los gobiernos de Marcos Pérez Jiménez en Venezuela, Gustavo Rojas Pinilla en Colombia, Rafael Odría en Perú, o el mismo Francois Duvalier en Haití. También al
} 
lucha política contra aquellos movimientos nacionales de ideología democrático - populista, y emprender campañas violentas contra los grupos radicales insurgentes. La política anticomunista se convirtió en la bandera de estos gobiernos, tanto en términos de política interna como en la internacional. Los compromisos vigentes de todos estos estados tributarios de los Estados Unidos correspondían a los asuntos de defensa hemisférica o seguridad continental frente a cualquier amenaza exterior del adversario hegemónico. Las amenazas no solo consistían en ofensas directas de intervencionismo pues estaban relacionadas con la posible emergencia de gobiernos populares, respaldados por la Unión Soviética y sus aliados. Este pronóstico fatalista servía de comodín para obviar pronunciamientos de rechazo frente a la violencia impartida por los regímenes militares contra las disidencias y hacía inevitable la continuidad en el respaldo diplomático, la ayuda militar y la asistencia económica de los Estados Unidos a los gobiernos pretorianos latinoamericanos.

Con la administración republicana de Eisenhower se estrecharían más los vínculos dependientes gracias al conocido respaldo de este partido a los regímenes de fuerza. Dentro de la estrategia de guerra total contra Moscú y ahora Pekín, para los Estados Unidos inspiraba mayor confianza un régimen militar que un gobierno democrático. La guerra de Corea y la amenaza del comunismo a nivel mundial generaron la necesidad de profundizar redes de apoyo y colaboración militar entre los ejércitos continentales sin intermediación de elementos civiles en los gobiernos, alentando la caída de los regímenes democráticos inestables y sospechosos para afianzar las relaciones de dependencia doctrinal, tecnológica y económica en contextos transformados por los gobiernos militares a partir de nuevas legislaciones represivas, campañas de pacificación interna, suspensión de partidos opositores y la desaparición de libertades democráticas.

La asistencia militar y económica fue una constante durante la era de los gobiernos militares, pues la guerra bipolar exigía tanto el incremento de la capacidad represiva de los aparatos estatales como llevar a cabo proyectos de infraestructura para el desarrollo. Para ambas apuestas se hacía vital el apoyo de los gobiernos norteamericanos, lógicamente esos compromisos tenían sus implicaciones en los grados de dependencia total o relativa, que asumían los países. En términos militares, los países que recibían apoyo de este tipo se veían forzados a recibir entrenamiento, adiestramiento y doctrina en centros norteamericanos, como las escuelas Randolph Field, Kelly Field, Fort Bening y la Academia de las Américas, ubicada en la zona del canal de Panamá, y a aceptar los lineamientos de la órbita del Programa de Ayuda Militar (PAM) del Pentágono, (Millet, 1984). En términos económicos, encaminar esfuerzos para la construcción de un desarrollo tipo occidental en sus economías, a partir de un crecimiento hacia adentro con el fin de evitar mayores niveles de conflictividad en sus sociedades producto de la pobreza y el hambre.

En las décadas que siguieron a la guerra mundial, el Pentágono no le había prestado mucha atención al hemisferio americano, su puesto estaba detrás de

gobierno del General Perón en Argentina, así este mostrara signos de mayor independencia frente a la proyectada hegemonía norteamericana. 
la URSS, Europa Occidental, el Medio Oriente, Japón y China en cuanto a términos de prioridades. Sin embargo, su debilidad e inestabilidad crónica originó un cierto temor que una potencia extranjera hostil e ideológicamente incompatible sacara provecho de esta debilidad para establecer una base en la región del Caribe desde la cual pudiera lanzar ofensivas contra los Estados Unidos. Por eso, desde la construcción del Canal de Panamá, Estados Unidos mantuvo una línea de bases, estaciones ambulantes de radar e instalaciones parecidas, además de una presencia naval considerable en la región.

Para mantener el acceso a las materias primas, productos primarios, mercados y reserva laboral existente en el hemisferio, era de vital importancia apoyar una política de comercio libre, mercados abiertos e inversiones norteamericanas fáciles y directas y para tales objetivos era necesario un apoyo a la estabilidad política de estos países, a fin de que se sustentaran los intereses fundamentales anteriormente expuestos. En general esta restricción fue interpretada como un pedido de apoyo a cualquier gobierno favorable a sus intereses que ocupara el poder, mientras también mantenía abiertas las líneas de comunicación a la oposición moderada, con el fin de encontrar interlocución si por alguna razón el gobierno de turno encontraba rechazo popular generalizado y debía ser cambiado por uno menos agresivo, pero igualmente sumiso.

Según comenta Howard Wiarda, en la obra de Ferry Diebel y John Gaddis, La Contención: concepto y política, la política internacional de los Estados Unidos había estado históricamente orientada a resolver crisis políticas en los países de la región. Esta política era esencialmente defensiva, como respuesta a las crisis después de que éstas habían ocurrido, en lugar de desarrollar una política más positiva, madura, a largo plazo y anticipadora. Para tal fin se acordó la estimulación de la democracia y los derechos humanos mediante una política fuerte, en la medida que los ayudase a asegurar la estabilidad y a proteger sus intereses fundamentales. El desarrollo económico y social se enfatizó en estos programas como medios complementarios y a la vez sólidos para preservar el orden imperante cuando las naciones del área estaban amenazadas por revoluciones populares radicales.

También es necesario aclarar que las fuerzas de contención y disuasión debían estar bien posicionadas en el mapa para responder frente a cualquier eventualidad que se presentase para intervenir cuando así lo ameritara la ocasión, tal y como sucedió reiteradas veces en esos años, como en 1954, cuando los Estados Unidos intervino junto con algunos gobiernos pretorianos latinoamericanos en Guatemala, ocasionando el derrocamiento del gobierno populista de izquierda de Jacobo Arbenz o en la intervención a la isla de Cuba tras la proclamación socialista de Castro en 1961, apoyando la invasión de tropas anticastristas en Bahía Cochinos con fuego aéreo y naval. Otro caso que podría ser nombrado es el de la intervención en la República Dominicana que le puso fin al gobierno socialdemócrata de Juan Bosch en 1965.

Wiarda señala que "Si bien el poder de fuego de la gran potencia norteamericana era demoledor para cualquiera de sus adversarios, sus capacidades y medios militares estaban acondicionados para conflictos de alta 
o mediana intensidad" (Diebel \& Gaddis, 1985, p. 187). Según estos autores, las fuerzas de combate norteamericanas habían sido mal diseñadas para los conflictos de baja intensidad, la suma de derrotas en este tipo de conflictos en el mundo colonial o semicolonial durante las décadas de vigencia de la Guerra Fría fueron múltiples. Agrega Wiarda que pese a que su equipamiento e inversión en este tipo de guerras fue mejorando con el tiempo por medio de operaciones especiales, asistencia en seguridad, inteligencia y comunicaciones, las unidades desplegadas para este tipo de conflictos en el denominado Tercer Mundo solían ser dotadas de equipos viejos, menos capaces y que requerían de más mano de obra para su empleo.

Estos vacíos en su capacidad militar mostraban una evidente debilidad y conllevaban a que sus enemigos o adversarios emplearan este tipo de recursos para lograr sus objetivos estratégicos. El triunfo de la revolución en Cuba empleando una guerra de guerrillas a gran escala sirvió de incentivo y modelo para las demás fuerzas revolucionarias en el continente. El apoyo soviético directo con el que contó el recién formado gobierno de Fidel Castro desde el año de 1961 y la crisis de los misiles en 1962, provocó una radicalización aún mayor de los Estados Unidos en sus medidas contra la isla. La cuarentena perpetua implicó la ruptura de las relaciones diplomáticas y la imposición de un embargo comercial decretado unilateralmente pero respaldado por muchos gobiernos latinoamericanos.

La administración Kennedy recurrió entonces a adoptar medidas para mitigar la radiación diseminada en la región por la experiencia de Cuba y su exitosa revolución. El lanzamiento de los Cuerpos de Paz y la Alianza para el Progreso, además de otros programas de desarrollo, estuvieron acompañados por programas de entrenamiento en contrainsurgencia para militares latinoamericanos y el apoyo directo en capacitación, armas y financiamiento a varios países para ayudar a derrotar a sus movimientos guerrilleros e incapacitar a los movimientos políticos de masas, cerrándoles los espacios de participación política, vía totalitarismos, que utilizaron la represión y el uso del terror policivo contra la disidencia o la ilegalidad política de opciones diferentes a los partidos tradicionales.

\section{La convivencia complaciente, necesidad de un líder anticomunista en el Estrecho de los Vientos (1957 - 1961)}

Las doctrinas anticomunistas promocionadas por el gobierno de Dwigt Eisenhower en los Estados Unidos y en el mundo sirvieron para justificar las políticas reales de conflicto militar abierto en la península coreana, el sudeste asiático y el Medio Oriente, e inclusive el Caribe durante las siguientes décadas. El patrocinio de regímenes militares aliados era una muestra evidente de que lo que se trataba de imponer era un modelo capitalista acompañado de gobiernos de facto para restarle fuerza a los partidos de corte populista e izquierdista, a partir del cierre de los canales de participación política democrática, la ilegalización de los partidos y de las vigencias constitucionales existentes. 
La era aguda de la guerra fría, (1949 - 1962), imponía nuevas formas de comportamiento en la política internacional, la mano dura propia del realismo político tuvo su máxima representación en el continente y aunque en buena parte de las décadas posteriores no decreció, esta etapa fue significativa en términos de represión estatal a las masas movilizadas en torno a los reclamos sociales propios de la modernidad. El terror generalizado se implementó por primera vez en América Latina, como estrategia concertada y científica además de efectiva. "En Haití se produjo la primera experimentación in situ del uso del terrorismo de Estado nutrido por las doctrinas de "seguridad nacional" y la lucha "contrainsurgencia" (Gerard, 1984, p. 21).

El ascenso de Duvalier al poder en Haití fue consecuencia de una crítica estabilidad política vivida por los gobiernos sucesivos desde 1956 y de un golpe militar que culminó con su entronación, por lo tanto, no fue necesario aparentar o usar máscaras protodemocráticas para engañar a la opinión pública internacional, ni mucho menos a las autoridades norteamericanas para encontrar recursos de inversión para el desarrollo. Sin embargo, para mitigar los escándalos, y proteger moralmente a sus aliados internacionales decidió demostrar su vocación democrática. El régimen naciente se empeñó en organizar un partido de gobierno llamado Parti pour l'Unité Nationale, que pronto ocupó los escaños y los puestos burocráticos. Este partido era semejante al Partido Dominicano utilizado por Rafael Leónidas Trujillo.

El acercamiento ideológico entre los presidentes Trujillo y Duvalier se expresó desde el principio, la sintonía de ambos gobernantes hacia el anticomunismo quedó plasmada en la reunión de la frontera binacional el 23 de diciembre de 1958, tal y como lo expone el diario La Nación de San José de Costa Rica, haciendo referencia a dicha reunión

Los presidentes de la República Dominicana y de Haití, firmaron hoy en Jimani y Malpasse (lados dominicano y haitiano de la frontera), un acuerdo que reitera el repudio de los dos países a la intervención extranjera en sus asuntos y se condena al comunismo internacional. Con este fin están dispuestos a no tolerar en sus respectivos territorios la presencia de ninguna organización ni de ningún individuo que realice actividades subversivas contra los estados signatarios, en particular la de los exiliados políticos, cuya acción perjudica las buenas relaciones entre dichos Estados, así como la propaganda sistemática por medio de la cual se incite al empleo de la fuerza o de la violencia (La Nación, 23 de diciembre de 1958).

El poder controlado por Duvalier contó desde el principio con el apoyo total de las fuerzas armadas de mayoría negra, amparadas en estas comenzó el ejercicio represivo, "implementó purgas al interior de las Fuerzas Armadas, represión contra las huelgas organizadas por la burguesía opositora, decretó el estado de sitio, la ilegalización de los demás partidos políticos y los medios de comunicación independientes, todo mediante la Ley Marcial del 27 de septiembre de 1957" (Gerard, 1969, p. 53). Los contendientes políticos vencidos fraudulentamente en elecciones, Louis Déjoie y Clement Jumelle fueron declarados por fuera de la ley, obligándolos a optar por el exilio o la clandestinidad. Sus amigos, seguidores de Dumarsais Estimé, antiguo 
presidente de Haití (1946 - 1950), fueron también forzados al exilio e inclusive su protector, el general Kebreu, tuvo que pedir asilo en la embajada de República Dominicana y aceptar el ofrecimiento del gobernante como embajador en Vaticano.

Para castigar a sus enemigos políticos que habían demostrado algún tipo de apoyo popular en las urnas durante las elecciones de 1957, el nuevo régimen armó procesos judiciales contra ellos. Ese año se convirtió en el año de los procesos políticos, algunos de los detenidos fueron condenados a muerte y otros fueron puestos en prisión bajo penas de tres a cinco años. Los jueces perdieron sus inmunidades de inamovilidad y se nombraron sustitutos por hombres incondicionales al mismo tiempo que empezaron las presiones de todo género contra los órganos de prensa que sostenían posiciones de inconformidad dentro de una oposición legalista y constitucional, algunos de ellos fueron cerrados e ilegalizados como: Foi Social, Mopisme Integral, Haïti Miroir, l'Independence y Le Patriote.

La dirigencia política de Haití, sus antiguos presidentes y demás personalidades de las fuerzas partidistas de la era pre duvalierista tuvieron entonces que buscar refugio en otros países y desde estos lanzar ofensivas diplomáticas buscando convencer a la opinión pública mundial acerca de los excesos del gobierno de Duvalier, las reiteradas violaciones a los derechos humanos y los métodos antidemocráticos que venía implementando contra cualquier manifestación de inconformidad de la oposición. Desde enero de 1959, el triunfo de la revolución contra el gobierno de Fulgencio Batista en la vecina isla de Cuba, permitió que el nuevo gobierno provisional de Manuel Urrutia, permitiera la llegada de algunos de las figuras connotadas de Haití.

El diario El Tiempo de Bogotá del 31 de enero del presente año hace referencia a esta situación:

Los exiliados Pierre Armand y Louis Déjoie anunciaron por radio que ha sido formado un frente revolucionario haitiano dedicado al derrocamiento del régimen de François Duvalier. Armand y Déjoie acusaron a Duvalier de haberse apropiado del poder en Haití hace 16 meses mediante unas elecciones amañadas y que, desde entonces ha malversado fraudulentamente 20 millones de dólares de las reservas del Banco de Haití. Simultáneamente el frente revolucionario envió un mensaje al Departamento de Estado de los Estados Unidos de América en el que dice que el triunfo de la revolución cubana demuestra sobradamente lo inútil y las consecuencias peligrosas de ayudar a regímenes tiránicos contra la voluntad unánime de los pueblos (El Tiempo, 31 de enero de 1959).

Aprovechando el clima de desconfianza que la revolución cubana suscitaba en el Pentágono, (pese a que inicialmente el gobierno de Urrutia en Cuba no despertaba sospechas de comunista), los gobiernos de la época tanto en el Caribe hispano como en Haití recurrieron a una diplomacia anticomunista que les sirvió de herramienta político ideológica para impedir cualquier querella con los Estados Unidos. La complicidad era compartida, pues el gobierno del presidente Eisenhower requería de los mismos argumentos paranoicos para captar apoyo en el Congreso, del cual dependía para una continuidad de la 
ayuda en pos de incrementar sus propósitos, no de endurecer el presupuesto militar, por el contrario rebajarlo pero "canalizando un incremento en la inversión en inteligencia, comunicaciones, entrenamientos $y$ todos los elementos consecuentes con los conflictos de baja intensidad" (Diebel \& Gaddis, 1995, p. 148). El objetivo era compartir la responsabilidad en el mantenimiento de la seguridad con sus aliados, capacitándolos, armándolos y dotándolos de los recursos económicos suficientes para la lucha contra el comunismo.

Duvalier se proclamó defensor de los ideales de la revolución de 1946 - 1956, (heredero de los gobiernos de Dumarsais Estimé y Paul Magloire), que continuaría en la lógica dispuesta a incluir a las masas mayoritarias negras en un proyecto nacionalista que reivindicara la cultura africana de la isla. El problema de Haití lo resumía a una falla en la estructura que no podía ser superada por medio de concesiones reformistas sino a partir de una renovación total y radical. Se proclamó desde el principio como una figura mesiánica que esperaba constituir un poder autocrático para conseguir sus objetivos providenciales. Se declaró a sí mismo interlocutor entre el pueblo y Dios, y representante de las voluntades del pueblo de Haití, de esta manera se reafirmó en la presidencia sin convocar elecciones, antes de ser declarado oficialmente como presidente vitalicio en 1964.

La ideología del régimen incluía una mezcla entre la propaganda colorista, los discursos populistas y la doctrina anticomunista. "El poder de los negros" (Labelle, 1987, pp. 21-37), la supuesta afirmación de los valores culturales africanos sirvió como instrumento útil dirigido a ocultar la contradicción histórica fundamental haitiana, la de los ricos y pobres, los opresores y oprimidos. A su familia la convirtió en una dinastía insular perpetua, con respaldo de amplios sectores universitarios, industriales, comerciantes y eclesiásticos, (estos últimos habían sido depurados de sacerdotes extranjeros y reemplazados por criollos, además, de ministros protestantes y de brujos del vodú).

La relación de Duvalier con la Iglesia Católica fue compleja durante su largo período. Algunas facciones indígenas de la Iglesia fueron recompensadas por su apoyo a la "revolución", otorgándoles cargos importantes en el Ministerio de Educación pero fueron las iglesias protestantes norteamericanas las que ganaron gran impulso, cubriendo el vacío dejado por el clero católico, al igual que reemplazando las relaciones históricas que la isla había mantenido con el Vaticano, por nuevas y profundas con sectores cristianos de los Estados Unidos. El resto de la jerarquía eclesiástica, en especial los sacerdotes y altos funcionarios del clero de origen extranjero conocieron abiertamente la hostilidad del régimen por causa de su supuesto activismo político pro - mulato y de la resistencia a la acelerada haitianización de sus cuadros criollos.

Según testimonio del sacerdote jesuita y rector de la Universidad Católica Andrés Bello en Caracas, Venezuela, "En el período de 1960 a 1964 se expulsaron de Haití varios ministros, como el Monseñor Poirier, los obispos Robert y Remy junto a otros seis padres franceses y dieciocho jesuitas francocanadienses, acusados de resistencia abierta al régimen e implicados en robos a los tesoros arqueológicos de la isla", (Ugalde, 1986, p. 163). Mientras se emprendió la disputa con la Iglesia Católica, Duvalier promocionó y defendió 
el vodú como una práctica religiosa auténtica, representante de las creencias y rituales ancestrales africanos. "El mismo Duvalier se convirtió en un brujo con el fin de ejercer una influencia considerable sobre el pueblo y el campesinado ignorante", (Briceño, 1989, p. 49).

El régimen duvalierista se convirtió en una dictadura partidista que respondía a la lógica de una mafia política arraigada en los tentáculos de la corrupción más atroz. A través de posiciones cargadas de favoritismos, el régimen adjudicaba puestos y beneficiaba con contratos a sus algunos individuos fieles. Sus colaboradores cambiaban de estatus social logrando acumular ventajas económicas y sociales, no por su capacidad cultural o personal, sino por su incondicional adhesión, verdadera o fingida a Papa Doc. Los empleados públicos fueron entonces destituidos de sus funciones en gran número y sus puestos adjudicados a cuadros duvalieristas fieles y caracterizados por su mediocridad, por los altos grados de corrupción en todas las esferas y por la reducción en la eficacia administrativa. La consecuencia más evidente, al mismo tiempo que preocupante, fue el enorme éxodo de la mano de obra profesional al exterior. La duvalierización significó "el reemplazo de los técnicamente capaces por los políticamente sumisos", (Cary, 1991, p.54). Los que emigraron, trataron de buscar soluciones a sus vidas en los países francoparlantes como Francia o Canadá y en los países latinoamericanos, especialmente Cuba, México o Venezuela.

El poder público en el gobierno de Duvalier se manifestó durante su tiranía con el único propósito de hacer cumplir sus designios y los de sus representantes 0 colaboradores. Todos los derechos ciudadanos: el derecho de opinión, de asociación, y de manifestación quedaron abolidos bajo el imperio de la fuerza bruta. Los otros poderes del estado, tanto el legislativo como el judicial perdieron autonomía y fueron absorbidos por el ejecutivo. Su poder desplazó a todas las demás instituciones, controlando todos los aspectos de la vida nacional e incluso la vida privada de los ciudadanos. En la prensa y en la radio las campañas anticomunistas acusaban a los militantes de querer subvertir el orden, de atentar contra la libertad y de amenazar la integridad del "mundo libre".

Tal y como lo presenta Gerard Jean Baptiste, embajador de Haití en Bogotá, en el siguiente enunciado, en el que trata de defender al gobierno que representaba, contra las voces de repudio de algunos columnistas del diario El Tiempo, el 28 de junio de 1961. Según las palabras del embajador,

los esfuerzos diarios del gobierno de la república de Haití para industrializar al país, luchar contra el analfabetismo, el llamamiento hecho por el presidente a la nación sin tomar en consideración cuestiones de color, y cuyos resultados hoy en día son una realidad concreta. Dios mediante, la paz y la seguridad reinan en todo el territorio nacional donde existen las mejores condiciones para la inversión de capitales extranjeros. Ninguna oportunidad ha sido dada a las ideologías subversivas de tomar pié y desarrollarse, por lo tanto, es un hecho indiscutible que Haití está participando de una manera efectiva al mantenimiento y al desarrollo de la gran democracia americana (El Tiempo, 28 de julio de 1961). 
Este parte oficial plagado de retórica contradecía cualquier versión de la oposición radicada en el exterior, además, servía para justificar la violencia política con tal de evitar la expansión de la revolución cubana hacia la otra gran isla de las Antillas. La paranoia entonces se convirtió en un recurso ideal para manipular al gobierno de los Estados Unidos y tramitar su apoyo económico continuo durante esos años. El 14 de agosto de 1960, el diario El Tiempo alertaba acerca de que una situación similar a la cubana podría presentarse en Haití,

\begin{abstract}
El presidente de Haití, François Duvalier, delicado de salud y perdiendo paulatinamente el firme dominio que en otros tiempos ejerció, afirma que solo una ayuda en masa de los Estados Unidos podrá salvar a su país de hondos trastornos sociales y políticos. El presidente y sus más íntimos colaboradores ponen de relieve que no hay más solución que esta, a menos que Washington quiera ver a Haití seguir la marcha de Cuba por la senda que conduce al campo comunista (El Tiempo, 14 de agosto de 1960).
\end{abstract}

La línea dura del régimen se manifestaba también con todo rigor en los liceos, las universidades, los centros de trabajo, y bajo la asesoría de los técnicos de la embajada norteamericana se tomaban medidas contrarrevolucionarias. El movimiento estudiantil fue reprimido y desarticulado, se promovieron las persecuciones a los jóvenes con ideas progresistas y se suprimieron los movimientos sindicales y las cooperativas de trabajadores. Su milimétrico anticomunismo era representado en las brutales campañas contra elementos tachados de revolucionarios y "comunistas", incluyendo a los miembros de la Unión de los Maestros de Enseñanza Secundaria, a estudiantes huelguistas en 1960 y a líderes visibles de la oposición, quienes fueron asesinados y torturados.

El terror sembrado por medio de centenares de asesinatos, muchos perpetuados a plena luz del día y en el trazado de las calles de las ciudades a los ojos del público, la desaparición de sospechosos, supuestos conspiradores contra el régimen, la toma de represalias contra sus familias, la exposición pública de cadáveres y el miedo a las detenciones y a la cárcel, apaciguaron los ánimos de la población. Hasta los exiliados se abstenían de tomar posiciones abiertas de denuncia pública en sus lugares de residencia por temor a la suerte que pudieran correr sus familias al interior de Haití. Las penas en las prisiones implicaban torturas constantes, además de desnutrición, enfermedades y psicosis, para finalizar en la eliminación física.

Las prisiones de Fort Dimanche, las celdas del Palacio Nacional, la Penitenciaría, las prisiones de los cayos, la de Cap Haitien, y de otras ciudades de provincia fueron llenadas continuamente. Según Antonin, "las jaulas sobrepasaban en horror a las jaulas de tigre, de Vietnam del sur", (Antonin, 1979, p. 74). En vista que las cárceles no daban abasto, mandó a construir nuevos cuarteles, el más famoso llevaba su nombre y era conocido por que sus celdas, de 3 metros de ancho por 2 de largo albergaban a varios prisioneros. En la prisión de Cayes, durante el año de 1957, "entre 18 de 20 prisioneros morían de hambre, los demás morían debido a las condiciones insalubres de las celdas o diezmados por las torturas y los malos tratos" (Antonin, 1979, p. 
78). Además de las masacres habituales dentro de los penales, existían aquellas de carácter extraordinario, tanto para conmemorar fechas simbólicas como las justificadas luego de cada tentativa de invasión o golpe de estado, o cuando las cárceles estaban repletas, para dar cabida a nuevos prisioneros.

Los comerciantes también sufrieron serios golpes, tradicionalmente organizados en gremios estos recurrían a las huelgas para oponerse a los gobiernos de turno, sin embargo durante este régimen aquellos que patrocinaban o participaban en las mismas eran reprimidos y sus almacenes abiertos por la fuerza y abandonados al pillaje. Además, Duvalier los obligaba a participar en el financiamiento de proyectos gubernamentales por medio de contribuciones espontáneas y directas. De negarse a hacerlo sus bienes eran destruidos o expropiados y sus propietarios detenidos y encarcelados. De esta manera, la Cámara de Comercio de Haití se convirtió en un organismo de canalización de fondos para concedérselos a las campañas de "renovación nacional" auspiciadas por el gobierno. La Asociación de Empleados Bancarios fue disuelta en su primer conflicto con el gobierno:
Quienes verdaderamente controlaron durante esta época el país fueron los empresarios extranjeros, quienes manipularon la economía de la nación y eran defendidos por las brigadas de milicias paraestatales, quienes por medio de la fuerza bruta hacían cumplir las decisiones arbitrarias de los poderosos (Fortuné, 1976, p. 267).

Con el fin de mantener un poder autocrático, Duvalier retiró a todos los oficiales de alto grado y los cambió por jóvenes, controlados y adiestrados por él mismo, ganando el apoyo del grueso de la tropa compuesto por nuevas generaciones de oficiales, de esta manera les impidió crear o consolidar partidos de influencia o base de apoyo dentro del aparato militar a los altos rangos. A fin de prevenir complots recurrió al despido masivo o a la ejecución sumaria de opositores, nombró directamente a los jefes de sección en las provincias y al mismo tiempo creó milicias fieles e independientes de la jerarquía militar en torno a su figura conformadas por castas populares, urbanas y rurales que le servían como contrapoder de las Fuerzas Armadas. Los ejércitos de paramilitares o VSN, Volontieres de la Sécurité Nationale, ${ }^{3}$, conocidos popularmente con Tontons Macoutes, fueron con el tiempo su base de apoyo fundamental, a quienes les confiaría la defensa tanto de su régimen como el de su hijo Jean Claude, o Duvalier II, en cuyo gobierno las milicias crecieron hasta convertirse en un ejército de 150.000 personas.

La creación de estas fuerzas de choque fue bastante temprana, el 22 de septiembre de 1959, como parte de los mecanismos que debía emplear el gobierno de Duvalier para evitar atentados provocados por los nuevos intentos de invasión desde el exterior que experimentaron tanto el régimen de Batista en Cuba desde el desembarco del Granma en 1956 y el reciente intento de la oposición dominicana frente a la dictadura de Rafael Leónidas Trujillo el 14 de

\footnotetext{
${ }^{3}$ Ver: Briceño Vásquez, Carlos. Haití, mito y realidad, Compendio de su historia política 1789 - 1988 , Caracas, 1989. (pp. $38-43$ ).
} 
julio de $1959^{4}$, con apoyo cubano. Ante este tipo de peligro, Duvalier intensificó sus medidas de seguridad. Aunque ya venían adiestrándose públicamente y sin máscaras desde junio de 1958, "los Tontons Macoutes aparecieron en el desfile militar junto a las tropas regulares, durante las manifestaciones de celebración de los dos años de Duvalier en el poder, el 22 de septiembre de 1959" (Gerard, 1969, p. 39), mejor dicho, como respuesta a la revolución de la isla vecina. La misión militar de los Estados Unidos y los oficiales haitianos más adictos a Duvalier impartieron adiestramiento técnico contrarrevolucionario a estos milicianos.

El diario El Tiempo, de Bogotá, reconocido como un medio de orientación liberal, hace referencia a la formación de estas fuerzas en el siguiente apartado,

Duvalier acompañó su advertencia ante una eventual invasión desde el exterior con la formación de una milicia civil que sigue muy de cerca la pauta señalada por el ejército popular de Castro. En lugar de los uniformes verde oliva de la revolución cubana, los voluntarios haitianos usan camisas azul pálido con brazaletes rojos y pantalones azul faena. Ostensiblemente, los 800 jóvenes de ambos sexos que integran la milicia están destinados a reforzar la guardia del palacio presidencial para defender a Duvalier de cualquier ataque interno y externo. Pero las autoridades advierten privadamente que su función principal consiste en contrarrestar el tradicional predominio del ejército haitiano y prevenir un levantamiento en masa (El Tiempo, 22 de septiembre de 1959).

Los Tontons Macoutes, eran siervos, mercenarios o matones del régimen, y si bien sus orígenes en términos mayoritarios correspondían a una extracción social popular, rural y urbana, también estaban compuestos por personas de diversa índole. Algunos habían salido de las filas de las clases dirigentes, terratenientes a nivel regional que reclutaban ejércitos para ejercer terror en zonas respectivas, otros eran antiguos oficiales ambiciosos de buscar fortuna, sedientos de autoridad y de poder, propensos a la criminalidad. También conformaban un grupo numeroso los campesinos llevados a jugar un papel oportunista, por la necesidad de ganarse la vida e incluso por la necesidad de protegerse del régimen. Estas milicias sin instrucción ni sentido de responsabilidad se atribuían funciones policiales, combinadas con actitudes por fuera de la ley, asestaban arrestos arbitrarios, persecuciones, ejecuciones sumarias, exterminio de familias enteras, extorsiones y otras actividades siniestras.

Sus masacres colectivas incluyeron a varios miles de habitantes de los barrios de Puerto Príncipe y de La Saline, como sucedió en la famosa matanza del 14 de marzo de 1960, cuando fueron ajusticiados cientos de campesinos y sus

\footnotetext{
${ }^{4}$ El 14 de julio de 1959 se presentó un desembarco de fuerzas opositoras al régimen de Trujillo en la República Dominicana. "Lucharemos hasta la muerte antes de rendirnos, declararon los últimos sobrevivientes del desembarco de rebeldes dominicanos, en respuesta al mensaje del ejército pidiendo su entrega. Los invasores fueron estimados en 20 a 25 de un total original de 65 . La guarnición regular del ejército en el sector, de unos 200 hombres, ha sido aumentada a unos 350, incluso tropas de montaña, además se ha bloqueado la pista de aterrizaje del lugar, para impedir nuevos desembarcos". En: $L a$ Nación. San José de Costa Rica, (15 de julio de 1959).
} 
viviendas destruidas en las fronteras de la República Dominicana como lo relata Antonin, "cuando los Tontons Macoutes quemaron todo aquello que encontraron a lo largo de la frontera a profundidad de un kilómetro", (Antonin, 1979 , p. 112). Vale resaltar que este régimen del terror se postergó en el tiempo como un fenómeno cotidiano, inclusive después de la época de análisis de este trabajo, durante los años finales de la década de 1960 y durante todo el régimen dinástico de Jean Claude Duvalier (Duvalier II o Baby Doc). Algunos de los sucesos importantes, como la disolución de las huelgas obreras y campesinas que desde 1963 hasta 1967, se sucedieron en diversas regiones y ciudades del país. Estas reclamaban tan solo una remuneración salarial en compensación de las horas de trabajo, mejores condiciones de vida y la vuelta a las garantías democráticas. Algunas de ellas terminaron con saldos en víctimas y posteriores despidos masivos, judicializaciones, expropiaciones y asesinatos selectivos.

En materia administrativa, el gobierno se caracterizó por la quiebra financiera, la malversación de los fondos públicos y la obvia incapacidad para aliviar la situación de miseria de la mayor parte de la población de la isla. Entre los años 1957 - 1959, Duvalier había expuesto que los supuestos objetivos de su gobierno consistían en proyectos de bienestar para las masas. Buscaba utilizar los créditos otorgados por los bancos norteamericanos para alfabetizar a los iletrados, desarrollar e intensificar la producción agrícola haitiana, aumentar la participación efectiva de las clases medias y campesinas al progreso de la nación, establecer las bases para la creación de una industria nacional y eliminar progresivamente la miseria del pueblo. Sin embargo, la ausencia de tales recursos tanto económicos como humanos y la rampante corrupción administrativa de sus funcionarios, impidió que se llevara a cabo la tan anunciada alfabetización y demás programas sociales encaminados a mejorar los niveles de vida de la población.

En 1958, Duvalier se mostró interesado en aliviar la vida cotidiana de los campesinos, mayoría de la población de la isla, con campañas de salud, alfabetización y habitación. Predicaba el lema que, "la tierra debería pertenecer a quien la trabajase", sin embargo, lo que sucedió fue exactamente lo contrario. Se agrandaron los dominios de los propietarios aliados del régimen, sobre todo en las regiones prósperas y fértiles de Artibonite, donde fueron expulsados los campesinos y labriegos de las tierras dominadas por el estado, éstas fueron puestas a disposición de los terratenientes y las compañías multinacionales, al mismo tiempo que se incrementaron las obligaciones tributarias de los campesinos. A muchos de ellos no les quedó otra salida que la migración a la República Dominicana para ofrecer su mano de obra en las plantaciones de caña de azúcar.

La política económica de Haití había tenido siempre como puntos cardinales la ayuda proveniente del exterior para poder desarrollarse, pero a medida que se incrementaban los préstamos y por ende las deudas contraídas, la economía haitiana encontraba cada vez menores posibilidades para cumplir con sus obligaciones. Sin medir las consecuencias del endeudamiento masivo para el futuro del país, en febrero de 1959 el gobierno de Duvalier solicitó 21 millones de dólares para nutrir de recursos al Fondo de Fomento del gobierno, el cual 
sería tan solo la primera parte de un total de 43 millones de dólares para cubrir el programa de fomento que tenía planeado concretar en dos años. "La deuda externa creció durante sus primeros años de gobierno, de 8.3 millones de dólares en 1957 a 39.7 millones durante el año de 1960", (Antonin, 1979, p. 41).

Pero pese a las limitaciones para efectuar los pagos, el año de 1959 fue proclamado por Duvalier como el año de la batalla económica,

esta vez, la corrupción administrativa, los gastos suntuarios del gobierno y la crisis financiera, producto de su administración ruinosa, los malos resultados en las cosechas del café y el descenso de los precios de las materias primas obstaculizaron dicho proyecto. Además, la inversión internacional y estatal decreció de un 8\% en 1957 a un 6\% en 1959 (Cary, 1991, p. 76).

Duvalier tenía el sueño de hacer de Haití un segundo Puerto Rico. La cooperación económica establecida con los Estados Unidos durante el gobierno de Eisenhower, entre los años 1957 - 1961, incluía una asistencia de parte de la USOM, United States Organizational Mission, que canalizaba fondos a través de un organismo llamado HADO, Haitian American Development Organization, para el financiamiento de dos grandes proyectos elaborados por técnicos norteamericanos. El proyecto Pote Cole de desarrollo regional pretendía integrar, modernizar y comerciar la economía agrícola de una vasta zona de 3250 kilómetros cuadrados de las mejores tierras del país, donde vivía el $12 \%$ de la población nacional. El otro macroproyecto era la irrigación y el desarrollo del valle de Artibonite, orientado a la producción de arroz para eliminar la importación, mermar el hambre que azotaba al pueblo y supuestamente llegar a exportar los excedentes.

Una muestra palpable del fracaso total de su administración en la promoción y financiación de programas sociales fue el descenso en el presupuesto en educación y los bajos niveles de alimentación del pueblo haitiano, tal y como lo revela Hector Cary, "A mediados de la década de 1960, Haití gastaba solo el $0.2 \%$ de su PIB en educación y su pueblo recibía el menor nivel de calorías diarias por habitante en el hemisferio americano" (1991, p. 72). Las gentes fueron ocupadas en las armas y en la construcción de Duvalierville, un complejo proyecto que tenía como fin la construcción de una nueva ciudad capital para el estado -ciudad que nació muerta y en la cual se invirtieron millones de dólares provenientes de las captaciones internacionales de capitales provenientes de los préstamos ofrecidos por las entidades financieras internacionales-.

Con el fin de mantener este apoyo constante y vital, el gobierno haitiano fue el primer gobierno de América en romper relaciones diplomáticas con la Cuba revolucionaria ${ }^{5}$ y nunca regateó su concurso y apoyo al bando norteamericano.

\footnotetext{
${ }^{5}$ El rompimiento se dio el día 30 de agosto de 1959. El embajador de Cuba en Port au Prince, Antonio Rodríguez Echázabal, fue acusado por las autoridades haitianas de haber conspirado contra en presidente François Duvalier. El embajador Echázabal había sido nombrado por el gobierno revolucionario cubano en ese enero, pero residía en Haití desde hacía 20 años. En: El Tiempo. Bogotá, (31 de agosto de 1959).
} 
"Su fidelidad fue puesta a prueba en las diversas conferencias interamericanas, donde Haití votó reiterativamente contra Cuba, ganándose el respaldo de la administración Eisenhower", (Castor, 1986, p. 54). Entretanto, la victoria definitiva de la guerra de guerrillas en Cuba, cuya costa este se encuentra a tan solo 45 kilómetros de Haití, fortalecía desde el exterior a la oposición haitiana, le daba fuerza moral y le brindaba un rocío de esperanza. La derrota de Batista abrió un agujero en el Caribe pareciendo presagiar el fin de las dictaduras vecinas, la de Trujillo y la de Duvalier, cómplices de la política de contención patrocinada por los Estados Unidos. Casi de inmediato, los ecos revolucionarios llegaron como las olas del mar, de manera inevitable, a las costas haitianas.

La revolución cubana ayudó generosamente y de diferentes maneras a la oposición haitiana, algunos no encontraron más remedio que cruzar el estrecho y adherirse al proyecto cubano fundiéndose con él pero nunca olvidando sus fuertes raíces impuestas por el idioma. La isla también sirvió de plataforma para lanzar ofensivas, según relata el mismo Antonin, "el 30 de agosto de 1959, treinta jóvenes cubanos y haitianos intentaron crear un foco armado al sur de Haití pero fueron derrotados", (Antonin, 1979, p. 86) ${ }^{6}$. Como se dijo anteriormente, las dictaduras vecinas de la isla de La Española estrecharon sus relaciones, pues el triunfo de la revolución cubana pretendía sacudir a ambos regímenes. Embarcados por la misma preocupación acerca del futuro y olvidando las anteriores rencillas que hubiesen podido existir históricamente entre sus países, ambos mandatarios se entrevistaron en dos ocasiones para concertar planes de acción conjunta para la defensa de la isla.

A raíz de esas entrevistas, quedó a cargo del ejército y la marina dominicanos, asegurar el patrullaje y la seguridad de las costas haitianas y la protección aérea de los dos países. Una estrecha colaboración política y policíaca, caracterizó este período. En cuanto al gobierno de Estados Unidos se refiere, su respaldo a ambos dictadores se consolidó. Eisenhower entendió que los métodos de terror implementados por Duvalier eran una garantía para la estabilidad, ya que como era lógico, la principal preocupación para su política en la región estaba dirigida a impedir la proliferación y expansión de las fuerzas revolucionarias anti norteamericanas que en toda América Latina habían sido alentadas por la revolución cubana. Desde enero de 1959, Milton Eisenhower, hermano del presidente Dwight, le aconsejaba la modificación del trato que el gobierno de los Estados Unidos daba a los hombres fuertes latinoamericanos, dándole un viraje que permitiera un accionar diferente.

Su carta, publicada por el periódico El Tiempo de Bogotá dice lo siguiente, "Creo que la sugerencia del vicepresidente Richard Nixon, hecha después de su viaje por Suramérica, es acertada y sería aplaudida por la propia América Latina: que demos un abrazo a los dirigentes democráticos y un apretón de

\footnotetext{
${ }^{6}$ En 1964 lo intentarían de nuevo bajo el mando de Fred Babtiste, cuyo movimiento armado fue bautizado simbólicamente bajo el nombre de FARH, tal y como se había llamado el movimiento guerrillero de la época de la intervención directa, esta vez el grupo tuvo más éxito logrando internarse en el Macizo de la Selle, logrando captar apoyo campesino. Sin embargo, pese a sus tímidos éxitos, tuvieron que abandonar el país por falta de aprovisionamiento hacía la República Dominicana, gobernada para entonces por el gobierno liberal de Juan Bosch.
} 
manos protocolario a los dictadores", (El Tiempo, (4 de enero de 1959). Milton Eisenhower manifestó además que no creía que los Estados Unidos debieran retirar o reducir sus programas de asistencia técnica, misiones diplomáticas, empréstitos $u$ otras actividades a países regidos por dictadores. Pero dijo, que los Estados Unidos tampoco deben condecorar a ningún dictador como han venido haciéndolo. La política internacional de los Estados Unidos hacia América Latina sufrió paulatinamente una transformación discursiva que posteriormente en los años de la administración de John F. Kennedy se materializó en la política de contención al comunismo a través del apoyo a los gobiernos democráticos.

\section{Duvalier I, un caso incómodo para las políticas de la Alianza para el Progreso (1961 - 1963)}

A principios de la era Kennedy, el 7 de abril de 1961 el ejecutivo haitiano promulgó un decreto que revocaba el mandato de los parlamentarios, pisoteando de esta manera su propia constitución de 1957 que fijaba los períodos en seis años. Las nuevas elecciones se efectuaron el 22 de abril, siendo los duvalieristas los únicos que se postularon para tener el privilegio de ocupar las 58 curules disponibles. Después del escrutinio, el gobierno hizo saber que su nombre figuraba en todos los votos emitidos, lo que supuestamente indicaba el deseo de toda la población y el territorio de reelegirlo para un nuevo período de seis años. Este improvisado plebiscito otorgó a Duvalier 1,328.000 votos. Se imponía entonces así un mayor radicalismo del régimen duvalierista frente a los intentos de reconstruir las democracias en la región, objetivo fundamental de la Alianza para el Progreso, proclamada por el gobierno demócrata recién posesionado.

La reacción internacional se materializó en el rompimiento de las relaciones diplomáticas por parte de las repúblicas de Venezuela y Costa Rica, seguidas después por la propia Gran Bretaña el 22 de mayo de 1961. Mientras crecía la hostilidad internacional frente a los gobiernos de facto en la región, la actitud del nuevo gobierno norteamericano se mostró muy blanda y contradictoria, en varias ocasiones se suspendieron oficialmente las ayudas monetarias al gobierno haitiano,

pero por "debajo de cuerda", y para que el público no lo supiera, la embajada norteamericana entregó secretamente a los representantes del gobierno, sumas especiales provenientes de los presupuestos de la misma misión diplomática", (Briceño, 1989, p. 53). "Pese a su inexperiencia e incapacidad notorias, Duvalier pudo mantenerse en el poder, principalmente por su máquina dictatorial y el apoyo multiforme de los Estados Unidos (Castor, 1986, p. 54).

Indiscutiblemente que la tácita aceptación de la dictadura duvalierista, tuvo su causa en la presencia de un gobierno comunista en las vecindades de la isla de Cuba. Por otra parte, siempre se ha dicho que a los gobiernos norteamericanos les han repugnado más las dictaduras de izquierda que las de derecha. Bajo estos preceptos, Duvalier aprovechó las circunstancias e hizo todo lo posible por mantener relaciones diplomáticas con Fidel Castro, temeroso de que éste 
siguiera dando apoyo en dinero o armas a sus enemigos, para que prepararan invasiones desde el vecindario. Pese a que se solidarizó con los demás países latinoamericanos y con los Estados Unidos rompiendo las relaciones diplomáticas con Cuba, conservó las consulares, con el fin de mantener un contacto estratégico que trataría de ganar ante alguna eventualidad futura frente al nuevo club de demócratas, el gobierno de Juan Bosch en República Dominicana, el de Rómulo Betancourt en Venezuela y el de John F. Kennedy, representante de su principal aliado hasta ese entonces.

Las transformaciones radicales efectuadas por Cuba y la era de la diplomacia abierta inaugurada por Fidel Castro con la Unión Soviética y los países del Este de Europa, habían venido a perturbar el viejo juego de las relaciones de dominio y dependencia entre Washington y las repúblicas latinoamericanas. Las relaciones entre la gran potencia americana y los demás países de la región a excepción de México habían permanecido desde el fin de la Segunda Guerra Mundial encubiertas dentro de la política de contención al comunismo, y se habían mantenido invariables a partir de la fórmula manipuladora del panamericanismo. Sin embargo, el impacto causado por el castrismo en América Latina originó un despertar en las masas y en las organizaciones patrióticas y revolucionarias, y alertó también a las oligarquías y al imperialismo para impedir por todos los medios, la independencia política y económica de las repúblicas antillanas, ístmicas y continentales del Caribe.

Desde 1960, debido al atentado de muerte fallido contra el gobernante venezolano Rómulo Betancourt fraguado según las fuentes analizadas por el dictador dominicano Rafael Leonidas Trujillo, las relaciones de poder entre las dictaduras de derecha y los nuevos gobiernos democráticos empezó a inclinarse a favor de un resurgimiento de gobiernos reformistas en la mayor parte de los países latinoamericanos. La declaración de guerra contra la dictadura de Trujillo, durante la Reunión de Cancilleres en San José de Costa Rica es muestra de ese cambio, al decidirse de manera general en el concierto de naciones americanas la suspensión de las relaciones diplomáticas con ese régimen. El ascenso de John F. Kennedy al poder en los Estados Unidos el 18 de enero de 1961 había sellado definitivamente la suerte de la más vieja de las dictaduras del Caribe. Desde su posesión como presidente de la principal potencia del mundo, Kennedy impulsó la eliminación de Trujillo, el más desprestigiado de los tiranos yancófilos. En palabras de Pierre Charles Gerard, "El objetivo final era tanto la desaparición de la Cuba revolucionaria, pesadilla del imperialismo norteamericano, como de todos los gobiernos militares del continente, considerados de facto y ajenos a la democratización que se quería imponer como regla general", (1969, p. 113).

El sacrificio de Trujillo era el precio que debía pagar Washington para sentar las bases morales de su doctrina de "democracia representativa", y la fórmula para justificar la destrucción de todas las dictaduras elitescas o populares en la región del Caribe. La muerte de Trujillo, el 30 de mayo de 1961 en la capital dominicana había sido planificada de manera simultánea a la invasión de Cuba, preparada en las selvas de Guatemala por opositores cubanos antifidelistas y el apoyo de elementos militares de los Estados Unidos. Sin embargo, pese al éxito de la primera operación, no se pudo conseguir la derrota de las fuerzas 
revolucionarias cubanas en abril del mismo año. El siguiente párrafo relata la manera como el ejército cubano de Fidel Castro logró impedir el éxito del desembarco,

Las fuerzas cubanas completaron hoy, la destrucción del grueso de la fuerza invasora que desembarcó en la costa sur - central de Cuba en la madrugada del lunes. Los invasores informaron que algunos de sus hombres llegaron al refugio de la Sierra de Escambray, a unos 80 kilómetros al este de la cabecera de puente establecida en la Bahía de Cochinos, para seguir luchando como guerrilleros, pero se cree que el grueso de la fuerza de invasión fue ya aniquilada", (El País, 18 de abril de $1961)^{7}$.

En agosto de 1961, durante la Conferencia Panamericana de Punta del Este, la tirantez entre Washington y Port au Prince se manifestó por primera vez. La Conferencia tenía como objetivo, condenar a la Cuba revolucionaria y tomar medidas para impedirle el camino a la revolución en el resto del continente. Las negativas de los principales países de América Latina, (Brasil, México, Argentina y otros como Chile, Bolivia y Ecuador) a la resolución condenativa, obligaba a los Estados Unidos a buscar el apoyo en los votos de los países pequeños. Haití, adoptando una posición ultranacionalista y en defensa a la soberanía se situó del lado de las voces del ejército haitiano y de los Tontons Macoutes o (VSN) de llegarlo a necesitar. De esta manera, Duvalier podía contar con el financiamiento parcial de su programa económico con las partidas giradas por el gobierno de Kennedy. El nuevo gobierno estadounidense asignó un presupuesto anual de 7 millones de dólares como fondos de asistencia económica y técnica, al mismo tiempo que US AID anunció un préstamo de 3.4 millones de dólares más para la construcción de carreteras. Esta ayuda tenía, según autores como Castor, Antonin y Gerard, objetivos de reforzar militarmente al gobierno de Duvalier para tomar medidas contra las milicias civiles armadas y las amenazas que representaban estas y su proyecto de toma del poder en la isla.

Duvalier tomó medidas para captar este apoyo económico cediendo la administración de los recursos al Congreso. De esta manera los Estados Unidos le otorgaron a Haití en el año de 1963, 28 millones de dólares, con los cuales el gobierno puso en marcha el proceso de liberalización económica, entendida como la adquisición o privatización de bienes públicos a precios cómodos, por los funcionarios públicos, los trabajadores civiles, las compañías nacionales y extranjeras y las compañías aseguradoras. Como respuesta el Fondo Monetario Internacional, le concedió recursos adicionales por el orden de 6 millones de dólares anuales en calidad de préstamos.

\footnotetext{
${ }^{7}$ El uso de cazas y tanques soviéticos suministrados a Castro y la participación de 1200 soldados del ejército cubano repelieron el intento de invasión, que arrojó como resultado 82 muertos y 743 presos que fueron recluidos en las cárceles cubanas. Los líderes fueron fusilados por el régimen castrista, que sumó estas víctimas a su gran prontuario de ejecuciones registradas en los primeros años de la revolución, justificadas en ser ejecutadas por tribunales revolucionarios frente aquellos considerados como enemigos de los ideales del nuevo gobierno proclamado desde ese momento abiertamente comunista. El intento de invasión fue infructuoso también debido al escaso compromiso del ejército, la marina y la aviación de los Estados Unidos. Kennedy no prestó la ayuda necesaria para la operación, las unidades desplegadas para transportar a los voluntarios cubanos eran viejas y sus armas anticuadas. Además de realizarse la operación desde Guatemala, la fuerza de combate fue reducida, subestimando la capacidad de reacción del ejército cubano y la creciente asistencia soviética.
} 
El 23 de febrero de 1963, ascendió al poder en la República Dominicana, Juan Bosch, prototipo del demócrata representativo soñado por Kennedy, quien ya manifestaba la desconfianza hacia el régimen de Duvalier. Este hecho permitió la euforia de los ánimos de la oposición haitiana tanto en Haití y como en el exterior, alentada tanto por Louis Déjoie como por Daniel Fignolé, quienes seguían visitando las antesalas de Washington. En el extranjero se comenzó a planear una maquinaria conspirativa que tendría como objetivo ponerle un final a la dictadura duvalierista por medio de una alianza entre el gobierno dominicano, la oposición política haitiana en el exilio y el Departamento de Estado de los Estados Unidos, liderada directamente por el presidente Kennedy.

La oposición haitiana y el Departamento de Estado recordaban entonces que el primer mandato de Duvalier, su "mandato constitucional", terminaba conforme a la Constitución de 1957, el 15 de mayo de 1963. Empezaron presiones diplomáticas y propagandísticas para obligar a Duvalier a reanimar la Constitución, ya casi muerta y enterrada. En principio, Duvalier sería forzado a aceptar las exigencias asegurando que ese día terminaría su mandato. Sin embargo, cuando llegó el día anunciado, Duvalier no solo no abandonó el poder, sino que pasó a la ofensiva, rebelándose contra los estadounidenses: "Además de darse cuenta de las maniobras secretas que se le estaban tendiendo, denunció internacionalmente las intenciones intervensionistas del gobierno Kennedy, expulsó al jefe de la Misión Militar norteamericana y obligó a salir al Embajador Raymond Thurstan de la isla", (Gerard, 1969, p. 120).

Los móviles serían distribuidos en el tablero, tanto al interior de Haití como en las fronteras próximas. Al interior, el Coronel Heinelt, jefe de la Misión Militar de los Estados Unidos en Haití y algunos miembros de la Embajada empezaron a mantener contactos con varios jefes militares del ejército haitiano, quienes recibieron instrucciones, garantías y ayuda para llevar a cabo la operación secreta. En abril de 1963 todo estaba listo para el golpe. En el exterior, Déjoie y Fignolé encabezaron un gobierno haitiano en el exilio desde Puerto Rico con apoyo diplomático de Kennedy, al mismo tiempo que se preparaba una invasión a Haití con los medios militares puestos a disposición por el presidente Juan Bosch y el respaldo de la Embajada de los Estados Unidos en República Dominicana.

Para evitar un eventual levantamiento interno que comprometiera a la propia institucionalidad militar, el ejército fue nuevamente purgado de muchos oficiales sospechosos: de los no incondicionales, de los que tenían demasiados nexos con la embajada norteamericana 0 de los que eran considerados excesivamente independientes. Con estas purgas el control de la seguridad del país terminó siendo controlado en mayor parte por los ejércitos de paramilitares, VSN o Tontons Mocoutes. Algunos activistas y propagandistas civiles anti duvalieristas fueron también aniquilados como forma de escarmiento y ejemplo ante las masas, de esta forma el gobierno logró sobrevivir a la conspiración y aprovechó la ocasión para aterrorizar a la disidencia. 
La alianza anti duvalierista tuvo que recurrir entonces a su estrategia de enfrentamiento directo, poniendo en funcionamiento sus móviles desde el exterior. En abril de 1963 se dio inicio al conflicto haitiano - dominicano. Con apoyo de Kennedy y de Bosch, se planeó una invasión militar contra Haití, contando con el líder León Cantave, ex - jefe del estado mayor del ejército, quien tenía a su disposición un número razonable de efectivos, armas y municiones, suficientes para comenzar los hostigamientos que serían apoyados por el ejército dominicano movilizado a la frontera y la fuerza aérea que sobrevolaría las ciudades haitianas con el fin de obligar a la dimisión de Duvalier.

El periódico El Tiempo de Bogotá registra el 5 mayo de 1963 el peligro de invasión que se sentía en Haití.

\begin{abstract}
Los informantes dijeron que la fuerza operativa comprende al portaviones Boxer. La formación abandonó anoche su posición de alerta en alta mar y avanzó por el canal de Saint Marc hasta más allá de la isla de Gonave, frente a la costa occidental de Haití. Otra importante formación anfibia se haya estacionada junto a la vecina isla de Puerto Rico, preparada para entrar en acción si estallaran desórdenes en Haití. Los preparativos norteamericanos trascendieron en momentos en que las fuerzas armadas dominicanas están concentradas a lo largo de la frontera y en el mar para invadir el territorio de Haití. Los dominicanos creen que podrán ocupar la capital haitiana en tres horas después de invadir el país por la frontera. Aviones a reacción y bombarderos medianos de la moderna fuerza aérea dominicana podrán llegar a Port au Prince desde la frontera en solo diez minutos (El Tiempo, 5 de mayo de 1963).
\end{abstract}

A pesar de los esfuerzos aliados contra Duvalier, este se había anticipado a los acontecimientos manteniendo una estrecha cooperación con la oposición dominicana, representada en la oligarquía y en las líneas ortodoxas del ejército trujillista. Tanto Reid Cabral, García Godoy y Joaquín Balaguer ejercían gran autoridad en el ejército dominicano y planeaban al mismo tiempo que la alianza antiduvalierista otro golpe de estado, pero contra el mismo gobierno de Juan Bosch. Con el fin de restarle popularidad, la derecha dominicana señaló al presidente Bosch como instrumento de los intereses norteamericanos. La falta de coordinación entre los efectivos o tal vez el pánico generado por el posible escándalo internacional impidieron que el embajador norteamericano en Santo Domingo, Mr. Martin, jugara un rol más importante en la ofensiva aliada. Cuando se iniciaron los enfrentamientos, éste le aseguró al presidente Bosch que Duvalier estaba a punto de partir en un avión de KLM con destino Argelia, donde aquel gobierno le había ofrecido asilo político.

Una posible explicación al fracaso de la operación es expuesta por Suzy Castor, quien afirma lo siguiente, "Este plan fracasó porque entre otros factores, el imperialismo daba pleno respaldo al dictador haitiano y porque los círculos oligárquicos del ejército dominicano ya maniobraban en contra del presidente Bosch, creándole grandes problemas internos", (Castor, 1983, p. 84). La incapacidad o la falta de determinación acabaron por corromper el intento más decidido de acabar con la dictadura haitiana, su fracaso terminó 
por fortalecer a Duvalier y postergar su régimen por otra década más, al mismo tiempo que la sucesión de su hijo, quien se prolongó en el poder hasta mediados de 1980.

La respuesta de Duvalier a este intento concertado entre sus aliados por despojarlo a la fuerza del poder, terminó definiendo un mayor radicalismo en sus posturas, ahora congraciándose con el tercermundismo y buscando acercamientos incoherentes con el gobierno cubano. La oposición interna y la externa fueron las mayores perjudicadas de este movimiento en la arena internacional. El 23 de agosto de 1963, la Asamblea Nacional de Haití suspendió la nacionalidad de los principales opositores al régimen. El informe consignado en el periódico El Tiempo dice lo siguiente, "La Asamblea Nacional de Haití privó hoy de la nacionalidad haitiana a los adversarios políticos del presidente François Duvalier y ordenó la confiscación de sus propiedades, acusándolos de ejecutar actos subversivos. La medida afecta a 55 dirigentes opositores que en su totalidad están en el exilio. Entre ellos figuran los ex presidentes Paul Magloire, Daniel Fignolé y Louis Déjoie", (El Tiempo, 24 de agosto de 1963).

El distanciamiento de Duvalier frente al gobierno Kennedy lo obligó a buscar ayuda económica en otros lugares del mundo como el Mercado Común Europeo, Japón, México, Israel y Canadá. Aunque en ninguno de estos lugares encontró el tan anhelado apoyo, por lo tanto se empezaron a difundir los rumores de que el dictador trataría de recurrir al bloque socialista para que lo sacaran del apuro. "Durante esos meses florecieron las fórmulas oratorias de tipo nacionalista, negrista y antinortemericano", (Gerard, 1969, p. 121). La diplomacia haitiana se inclinó a tender relaciones con los nuevos estados africanos en el seno de la Organización de las Naciones Unidas con muy poco éxito. Sin embargo, en los meses posteriores, Duvalier se acotó dos grandes victorias en la arena internacional; la primera fue cuando Juan Bosch fue víctima de un golpe militar el 25 de septiembre de 1963 y la segunda, cuando J.F. Kennedy fue asesinado el 22 de noviembre del mismo año. La suerte volvió a inclinarse a su favor.

En abril de 1964 se comenzaron a difundir rumores relacionados con el interés de Duvalier en nombrarse presidente vitalicio. Para tal cometido, se formó una nueva Asamblea Constituyente que el 25 de mayo de 1964 aprobó una nueva Constitución, en la cual una disposición expresa otorgaba a Duvalier el título de presidente vitalicio. Dicha disposición debería ser sometida a ratificación popular en el término de 15 días. La farsa electoral permitió que el referéndum previsto en el decreto se efectuara el 14 de junio. Según los informes oficiales manejados por los autores Antonin y Gerard en sus obras, ese referéndum arrojó $2,8000.000$ de votos en pro y solo 2.230 en contra.

La investidura de Duvalier como presidente vitalicio se efectúo finalmente el 22 de julio de 1964. Las nuevas administraciones norteamericanas encontraron fácilmente canales de entendimiento con el régimen. La ayuda a Duvalier ascendió de nuevo con una vigorosa vitalidad durante el periodo presidencial de Lyndon Johnson alcanzando entre los años 1963 - 1968 la cifra de 4.4 millones de dólares como promedio anual. Tanto el gobierno de Johnson como 
el posterior gobierno de Nixon, fortalecieron al régimen bajo el lema de que era mejor Francois Duvalier, o en su ausencia su hijo Jean Claude que cualquier otro para mantener el orden y la paz en Haití. Esas administraciones norteamericanas no escatimaron esfuerzos para darle impulso y legitimidad a los Duvalier, incluso traspasando las fronteras de la muerte. Pues cuando Papa Doc desapareció de este mundo, "la marina norteamericana se concentró en las costas de Haití, sobre todo en Puerto Príncipe, con el objetivo de apoyar a su hijo Jean Claude, Duvalier II, en la sucesión al trono, impidiendo todo posible levantamiento en su contra", (Fortuné, 1976, p. 320).

\section{Conclusiones}

En este pequeño trabajo queda claro cómo para estudiar y comprender la evolución de los procesos políticos y la naturaleza de los regímenes en las repúblicas insulares del Caribe es desde todo punto de vista necesario conocer las políticas internacionales favorecidas por Washington y sus gobiernos de turno. Pese a la distancia ideológica existente entre los presidentes Eisenhower y Kennedy, las políticas de contención al comunismo propias de la época influyeron de manera sorprendente en las directrices adoptadas por ambos gobiernos. Tal vez hayan existido distancias en sus métodos de acción, pues Eisenhower promovía abiertamente los gobiernos militares y las tiranías personalistas a lo largo y ancho del hemisferio, mientras Kennedy, dispuesto a enfrentar a la revolución cubana por otros medios más democráticos y reformistas buscó presionar a los gobiernos dictatoriales de derecha, tratando de encontrar un equilibrio moral que surtiera efecto en pos de un respaldo general a la democracia representativa, acorde con los principios expuestos en su doctrina de la Alianza para el Progreso.

La lógica de la guerra fría favorecía las concepciones más realistas u ortodoxas en el manejo de la política exterior norteamericana y tras el breve período de Kennedy, la situación volvería a la normalidad acostumbrada por los gobiernos norteamericanos para el hemisferio. El patrocinio a las oligarquías y a los sectores militares como fieles aliados en la cruzada contra el "comunismo", favoreciendo la cooperación económica y diplomática que mantuviera a raya a las guerrillas y a las movilizaciones populares en su carrera de ascenso al poder en los países latinoamericanos. La asistencia económica vía donaciones o empréstitos favoreció la perdurabilidad de gobiernos antipopulares y la definición capitalista o por lo menos favorable al capitalismo, en las orientaciones económicas, garantizó la profundización de la dependencia tecnológica y financiera de las repúblicas latinoamericanas frente a los Estados Unidos. El respaldo militar endureció las medidas contrainsurgentes conllevando a la región al alejamiento y a la fractura de los canales de participación democrática y del respaldo a la defensa de los derechos humanos.

\section{Referencias bibliográficas}

Fuentes Documentales 
El Tiempo. (1959, 1960, 1961, 1963). Bogotá.

La Nación. (1958, 1959). San José.

El País. (1961). Cali.

\section{Fuentes bibliográficas}

Antonin, Arnold. (1979). La lucha del pueblo de Haití. Caracas: Editorial Ateneo de Caracas.

Antonin, Arnold. (1981). "Haití: Liberalización y terrorismo de Estado". En Revista Nueva Sociedad, № 52.

Antonin, Arnold. (1983). "Haití en el Caribe". En Revista Nueva Sociedad, № 63.

Arciniegas, Germán. (1996). Entre la libertad y el miedo. Bogotá: Planeta.

Barrenechea, Mauro. (1977). "Haití la ignorada". En Revista Nueva Sociedad, Vol. 40, № 396, Caracas.

Bemis, Samuel Flagg.(1950). Diplomatic History of the United States. New York: Henry Holt \& Company.

Briceño Vásquez, Carlos. (1989). Haití, mito y realidad, Compendio de su Historia Política entre 1789 - 1988. Caracas.

Cary, Hector. (1991). Une quête du politique, essais sur Haittí. Montréal: Editions Henri Des Champs.

Castor, Suzy. (1971). La ocupación norteamericna de Haití y sus consecuencias, (1915 - 1934). México: Siglo XXI Editores.

Castor, Suzy. (1983). Migración y relaciones internacionales, el caso haitiano dominicano. México: Universidad Autónoma de México.

Castor, Suzy. (1986). "Haití, de la ruptura a la transición". En Revista Nueva Sociedad, № 82.

Chapman, Charles. (1927, Agosto).. "The Development of the intervention in Haiti". En: Hispanic American Historical Review. Tomo VIII, N.3.

Diebel, Terry y Gaddis, John (compiladores). (1995). La Contención: concepto y política. México: Grupo Editorial Latinoamericano.

Escobar; Arturo. (1996). La invención del Tercer Mundo. Construcción y reconstrucción del desarrollo. Bogotá: Editorial Norma.

Fortuné, Georges. (1976). Haití, una nación al servicio del 50\%. Caracas: Gráfico Formateca. 
Gerard Pierre, Charles. (1969). Radiografía de una dictadura, Haití bajo el régimen del Doctor Duvalier. México: Editorial Nuestro Tiempo.

Gerard Pierre, Charles. (1999). Haití: pese a todo la Utopía. México: Siglo XXI Editores.

Gerard Pierre, Charles. "Haití, la procesión va por dentro", Entrevista realizada por la Revista Nueva.

Recibido: 16 de abril de 2010.

Aprobado: 18 de noviembre de 2010. 
